Pacific Journal of Mathematics

O. GRo 


\title{
TWO-GROUPS AND JORDAN ALGEBRAS
}

\author{
JAMES E. WARD, III
}

Stroud and Paige have introduced an important class of central simple Jordan algebras $B\left(2^{n}\right)$ of characteristic two. This paper determines the automorphism groups of the algebras $B\left(2^{n}\right)$ and, in so doing, produces an infinite family of finite 2-groups. This is accomplished by characterizing the automorphisms of $B\left(2^{n}\right)$ as matrices operating on the natural basis for the underlying vector space of $B\left(2^{n}\right)$ and then using this characterization to obtain generators and commuting relations for the automorphism groups.

Throughout the paper let $q=2^{n-2}, r=2^{n-1}, s=2^{n}$, and $t=2^{n+1}$. $\delta_{i, j}$ is the Kronecker delta.

1. The algebras. In 1965 J. B. Stroud [3], pursuing some earlier work of E. C. Paige [2], defined the following class of vector spaces and proved that they are central simple Jordan Algebras of characteristic two:

DEFINITION. Let $B\left(2^{n}\right)$ for $n \geqq 2$ be the vector space over the field $Z_{2}$ of two elements with basis $u_{-1}, u_{0}, u_{1}, \cdots, u_{s-2}, v_{1}, v_{2}, \cdots, v_{s}$ and with multiplication in $B\left(2^{n}\right)$ defined inductively as follows:

The products $u_{i} u_{j}$ for $-1 \leqq i, j \leqq s-2$ are defined by:

(1) $u_{0} u_{i}=u_{i}$ for $-1 \leqq i \leqq s-2$,

(2) $u_{-1}^{2}=0, u_{-1} u_{i}=u_{i-1}$ for $0 \leqq i \leqq s-2$,

(3) $u_{i} u_{j}=u_{j} u_{i}$ for $-1 \leqq i, j \leqq s-2$,

(4) $u_{1}^{2}=u_{2}^{2}=u_{1} u_{2}=0$.

Assuming the products $u_{i} u_{j}$ are defined for $-1 \leqq i, j \leqq 2^{k}-2$ where $2 \leqq k \leqq n-1$, let $p=2^{k}$ and define

(5) $u_{p+i} u_{j}=H_{i, j} u_{p+i+j}$ when $u_{i} u_{j}=H_{i, j} u_{i+j}, j \neq-1$ with $H_{i, j}$ in $Z_{2}$,

(6) $u_{p+i} u_{p+j}=0$.

For $k \geqq 1, m \geqq 0, p=2^{k}$, define the products $u_{i} v_{j}$ by:

(7) $u_{i} v_{j}=v_{j} u_{i}$ for $-1 \leqq i \leqq s-2,1 \leqq j \leqq s$,

(8) $u_{0} v_{j}=v_{j}$ for $1 \leqq j \leqq s$,

(9) $u_{-1} v_{j}=v_{j}+v_{j-1}, v_{0}=0$ for $1 \leqq j \leqq s$,

(10) $\quad u_{p-1} v_{(2 m) p+j}=v_{(2 m+1) p+j-1}+v_{(2 m+1) p+j}$ for $1 \leqq j \leqq p$,

(11) $u_{p+i} v_{(2 m) p+j}=d_{i, j} v_{(2 m+1) p+i+j}+e_{i, j} v_{(2 m+1) p+i+j+1}$

when

(12) $u_{i} v_{j}=d_{i, j} v_{i+j}+e_{i, j} v_{i+j+1}$ for $0 \leqq i \leqq p-2,1 \leqq j \leqq p$ and $d_{i, j}$, $e_{i, j}$ in $Z_{2}$,

$u_{p+i} v_{(2 m+1) p+j}=0$ for $-1 \leqq i \leqq p-2,1 \leqq j \leqq p$. 
Finally, define the products $v_{i} v_{j}$ by:

(14) $v_{i} v_{j}=v_{j} v_{i}$ for $1 \leqq i, j \leqq s$,

(15) $v_{2}^{2}=u_{0}$,

$$
\begin{aligned}
v_{1} v_{j}= & \left\{\begin{array}{l}
u_{j-3}+u_{j-2}, j \text { even } \\
u_{j-3}, j \text { odd }
\end{array}\right. \\
& \text { where } u_{j}=0 \text { for } j<-1,
\end{aligned}
$$

when

(18) $v_{i} v_{j}=D_{\imath, j} u_{i+j-4}+E_{i, j} u_{i+j-3}$ for $1 \leqq i \leqq p, 2 \leqq j \leqq p$ and $D_{i, j}$, $E_{i, j}$ in $Z_{2}$,

(19) $v_{p+i} v_{p+j}=0,1 \leqq i, j \leqq p$.

From this definition it is clear that $B\left(2^{n}\right)$ is commutative ((3), (7), (14)) and that $u_{0}$ is its identity element ((1), (8)). Moreover, for all $i, j, a, b$ (i.e., $-1 \leqq i, j \leqq s-2$ and $1 \leqq a, b \leqq s$ ),

$$
\begin{aligned}
& u_{i} u_{j}= h_{i, j} u_{i+\jmath} \text { where } h_{i, j}=0 \text { or } 1, \\
& u_{i} v_{a}=\left\{\begin{array}{l}
g_{i, a}\left(v_{i+a}+v_{i+a+1}\right), v_{0}=0, \text { when } i \equiv 1(\bmod 2) \\
g_{i, a} v_{i+a} \text { when } i \equiv 0(\bmod 2)
\end{array}\right. \\
& \text { where } g_{\imath, a}=0 \text { or } 1, \text { and } \\
& v_{a} v_{b}=\left\{\begin{array}{l}
f_{a, b} u_{a+b-4} \text { when } a \equiv b(\bmod 2) \\
f_{a, b}\left(u_{a+b-4}+u_{a+b-3}\right) \text { when } a \neq b(\bmod 2)
\end{array}\right. \\
& \text { where } f_{a, b}=0 \text { or } 1 .
\end{aligned}
$$

\begin{tabular}{|c|c|c|c|c|c|c|c|c|}
\hline & $u-1$ & $u_{0}$ & $u_{1}$ & $u_{2}$ & $v_{1}$ & $v_{2}$ & $v_{3}$ & $v_{4}$ \\
\hline$u-1$ & 0 & $u-1$ & $u_{0}$ & $u_{1}$ & $v_{1}$ & $v_{1}+v_{2}$ & $v_{2}+v_{3}$ & $v_{3}+v_{4}$ \\
\hline$u_{0}$ & $u-1$ & $u_{0}$ & $u_{1}$ & $u_{2}$ & $v_{1}$ & $v_{2}$ & $v_{3}$ & $v_{4}$ \\
\hline$u_{1}$ & $u_{0}$ & $u_{1}$ & 0 & 0 & $v_{2}+v_{3}$ & $v_{3}+v_{4}$ & 0 & 0 \\
\hline$u_{2}$ & $u_{1}$ & $u_{2}$ & 0 & 0 & $v_{3}$ & $v_{4}$ & 0 & 0 \\
\hline$v_{1}$ & $v_{1}$ & $v_{1}$ & $v_{2}+v_{3}$ & $v_{3}$ & 0 & $u-1+u_{0}$ & $u_{0}$ & $u_{1}+u_{2}$ \\
\hline$v_{2}$ & $v_{1}+v_{2}$ & $v_{2}$ & $v_{3}+v_{4}$ & $v_{4}$ & $u-1+u_{0}$ & $u_{0}$ & $u_{1}+u_{2}$ & $u_{2}$ \\
\hline$v_{3}$ & $v_{2}+v_{3}$ & $v_{3}$ & 0 & 0 & $u_{0}$ & $u_{1}+u_{2}$ & 0 & 0 \\
\hline$v_{4}$ & $v_{3}+v_{4}$ & $v_{4}$ & 0 & 0 & $u_{1}+u_{2}$ & $u_{2}$ & 0 & 0 \\
\hline
\end{tabular}

The multiplication table for $B(4)$ is easily computed to be

and the following table summarizes the inductive definition of $B(2 p)$. if the multiplication table of $B(p)$ is known: 


\begin{tabular}{|c|c|c|c|c|}
\hline & $u_{-1} \cdots u_{p-2}$ & $u_{p-1} \cdots u_{2 p-2}$ & $v_{1} \cdots v_{p}$ & $v_{p+1} \cdots v_{2 p}$ \\
\hline \multirow{3}{*}{$\begin{array}{c}u_{-1} \\
u_{0} \\
\vdots \\
u_{p-2}\end{array}$} & \multirow{3}{*}{ KNOWN } & (2) & \multirow{3}{*}{ KNOWN } & (9) \\
\hline & & (1) & & (8) \\
\hline & & (5) & & $\begin{array}{l}(10),(11),(13) \\
\text { with smaller } \\
\text { values of } p\end{array}$ \\
\hline \multirow{2}{*}{$\begin{array}{c}u_{p-1} \\
\vdots \\
u_{2 p-2}\end{array}$} & \multirow[b]{2}{*}{$\underset{(3)}{\text { COMMUTATIVITY }}$} & \multirow[b]{2}{*}{$\underset{(6)}{\text { ZERO }}$} & (10) & \multirow[b]{2}{*}{$\begin{array}{c}\text { ZERO } \\
(13)\end{array}$} \\
\hline & & & (11) & \\
\hline \multirow{2}{*}{$\begin{array}{c}v_{1} \\
\vdots \\
v_{p}\end{array}$} & \multirow[b]{2}{*}{ KNOWN } & \multirow[b]{2}{*}{$\underset{(7)}{\operatorname{COMMUTATIVITY}}$} & \multirow[b]{2}{*}{ KNOWN } & (16) \\
\hline & & & & (17) with (14) \\
\hline $\begin{array}{c}v_{p+1} \\
\vdots \\
v_{2 p}\end{array}$ & $\underset{(7)}{\text { COMMUTATIVITY }}$ & $\begin{array}{c}\text { ZERO } \\
\text { ((13) with (7)) }\end{array}$ & $\underset{(14)}{\text { COMMUTATIVITY }}$ & $\underset{(19)}{\mathrm{ZERO}}$ \\
\hline
\end{tabular}

The numbers indicate the equation used to determine the particular block of the multiplication table, COMMUTATIVITY in a block means that the block in question is determined from a corresponding block by the commutativity of $B\left(2^{n}\right)$, and ZERO denotes a block all of whose entries are zero.

\section{The automorphisms.}

Definition. Define a set of $t \times t$ matrix forms $A_{n}$ for $n \geqq 2$ inductively as follows: Let

$$
A_{2}=\left[\begin{array}{llllllll}
1 & a_{0} & a_{1} & a_{2} & 0 & a_{0} & 0 & b_{4} \\
0 & 1 & 0 & 0 & 0 & 0 & 0 & 0 \\
0 & 0 & 1 & a_{0} & 0 & 0 & 0 & a_{0} \\
0 & 0 & 0 & 1 & 0 & 0 & 0 & 0 \\
0 & a_{0} & 0 & b_{4} & 1 & a_{0} & a_{1} & a_{1}+a_{2} \\
0 & 0 & 0 & 0 & 0 & 1 & 0 & 0 \\
0 & 0 & 0 & a_{0} & 0 & 0 & 1 & a_{0} \\
0 & 0 & 0 & 0 & 0 & 0 & 0 & 1
\end{array}\right]
$$

where $a_{0}, a_{1}, a_{2}$ and $b_{4}$ are in $Z_{2}$.

Assuming that the matrix $A_{n}=\left(c_{i, j}\right)$ where $-1 \leqq i, j \leqq t-2$ is defined in terms of elements $a_{e}$ and $b_{m}$ of $Z_{2}$ with $0 \leqq e \leqq s-2$ and 
$0 \leqq m \leqq s$, we define the matrix $A_{n+1}=\left(d_{i, j}\right)$ for $-1 \leqq i, j \leqq 2 t-2$ in terms of elements $a_{e}$ and $b_{m}$ of $Z_{2}$ with $0 \leqq e \leqq t-2$ and $0 \leqq m \leqq t$ as follows: For $-1 \leqq i, j \leqq s-2$,

(i ) $\quad d_{i, j}=d_{i+s, j+s}=c_{i, j}$.

(ii) $d_{i, j+t}=d_{i+s, j+3 s}=c_{i, j+s}$.

(iii) $d_{i+t, j}=d_{i+3 s, j+s}=c_{i+s, j}$.

(iv) $d_{\imath+t, j+t}=d_{i+3 s, j+3 s}=c_{i+s, j+s}$.

(v) $\quad d_{i+s, j}=d_{i+s, j+t}=d_{i+3 s, j}=d_{i+3 s, j+t}=0$.

(vi) $\quad d_{i, j+s}=\left\{\begin{array}{l}0 \text { if } i=j \\ p_{i, j} a_{e+s} \text { if }\end{array}\right.$

(vii) $d_{i, j+3 s}=p_{i, j+s} b_{m+s}$ where $p_{i, j+s}$ is in $Z_{2}$ and $c_{i, j+s}=p_{i, j+s} b_{m}$ with $a_{0}=b_{2}$.

(viii) $d_{i+t, j+s}=p_{i+s, j} b_{m+s}$ where $p_{i+s, j}$ is in $Z_{2}$ and $c_{i+s, j}=p_{i+s, j} b_{m}$ with $a_{0}=b_{2}$.

$$
\text { (ix) } \quad d_{i+t, j+3 s}=\left\{\begin{array}{l}
0 \text { if } i=j \\
p_{i+s, j+s} a_{e+s}+q_{i+s, j+s} a_{e+s+1} \text { if } i \neq j
\end{array}\right.
$$

where $p_{i+s, j+s}$ and $q_{i+s, j+s}$ are in $Z_{2}$ and $c_{i+s, j+s}=p_{i+s, j+s} a_{e}+q_{i+s, j+s} a_{e+1}$ with the convention that if $c_{\imath+s, j+s}=a_{w}$, then $e=w$.

The matrices $A_{n}$ can be summarized by the following figure. If the $2^{k} \times 2^{k}$ matrix $A_{k}$ is known, then $A_{k+1}$ is the $2^{k+1} \times 2^{k+1}$ matrix given in block form by

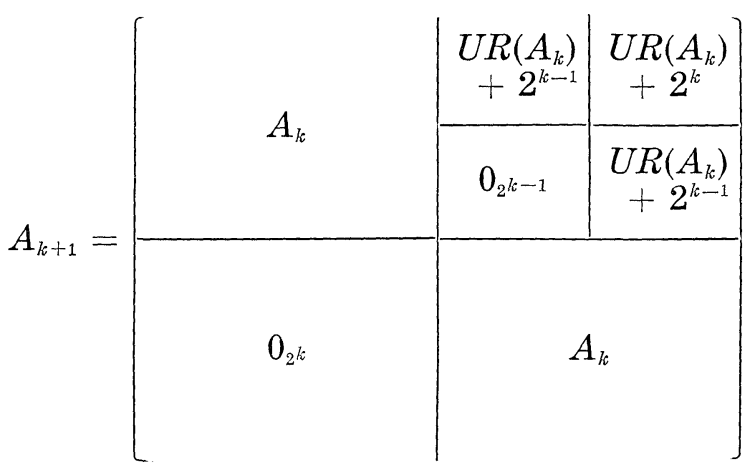

where, for $m=2^{k-1}$ or $2^{k}, 0_{m}$ is the $m \times m$ zero matrix and $U R\left(A_{k}\right)+m$ is the $2^{k-1} \times 2^{k-1}$ matrix obtained by adding $m$ to each subscript of the $2^{k-1} \times 2^{k-1}$ block in the upper right hand corner of $A_{k}$ under the convention that if an entry in the upper right hand block of $A_{k}$ is zero, then the corresponding entry in $U R\left(A_{k}\right)+m$ is also zero.

We now prove the characterization theorem.

THEOREM. A linear transformation $A$ of the Jordan algebra $B\left(2^{n}\right)$ over $Z_{2}$ with $n \geqq 2$ is an automorphism of $B\left(2^{n}\right)$ if and only 
if its matrix relative to the canonical basis of $B\left(2^{n}\right)$ is of the form $A_{n}$.

Proof. The proof is outlined by several lemmas.

First we establish some general results about the automorphisms of $B\left(2^{n}\right)$. If $A$ is an automorphism of $B\left(2^{n}\right)$ with matrix $\left(c_{i, j}\right)$, $-1 \leqq i, j \leqq t-2, c_{i, j}$ in $Z_{2}$, relative to the canonical basis of $B\left(2^{n}\right)$ then we can show:

LEMMA 1. $c_{i, j}=c_{i, s+j}=c_{s+i, j}=c_{s+i, s+j}=0$ for $-1 \leqq j<i \leqq s-2$.

LEMma 2. $c_{i, i}=1$ for $-1 \leqq i \leqq t-2$ and $c_{i, s+i}=c_{s+i, i}=0$ for $-1 \leqq i \leqq s-2$.

Lemma 3. $c_{i, j}=\delta_{i, j}$ for $-1 \leqq i, j \leqq t-2$ and $i \equiv 0(\bmod 2)$.

Lemma 4. $c_{i, s+j}=c_{s+i, j}$ for $-1 \leqq i, j \leqq s-2$. In particular, $c_{i, s+j}=c_{s+i, j}=0$ for $-1 \leqq i, j \leqq s-2$ and $j \equiv 1(\bmod 2)$.

LEMMA 5. For $-1 \leqq i, j \leqq r-2, c_{i, j}=c_{r+i, r+j} ; c_{i, s+j}=c_{r+i, 3 r+j}$; $c_{s+i, j}=c_{3 r+i, r+j}$; and $c_{s+i, s+j}=c_{3 r+i, 3 r+j}$.

LEMMA 6. For $-1 \leqq i \leqq j \leqq r-2$,

(i) $c_{i, r+j}=\left\{\begin{array}{l}0 \text { if } i=j \\ p_{i, j} c_{-1, r+j-i-1}\end{array}\right.$ if $i \neq j$ if $c_{i, j}=p_{i, j} c_{-1, j-i-1}$ where $p_{i, j}$ is in $Z_{2}$.

(ii) $c_{i, 3 r+j}= \begin{cases}0 & \text { if } i=j \\ q_{i, j} c_{-1,3 r+j-i-1} & \text { if } i \neq j\end{cases}$ if $c_{i, s+j}=q_{i, j} c_{-1, s+j-i-1}$ where $q_{i, j}$ is in $Z_{2}$.

(iii)

$$
c_{s+i, 3 r+j}=\left\{\begin{array}{l}
0 \text { if } i=j \\
m_{i, j} c_{-1, r+j-i-1}+k_{i, j} c_{-1, r+j-i-2} \text { if } i \neq j \text { and } j \equiv 0 \\
(\bmod 2) \\
m_{i, j} c_{-1, r+j-i-1} \text { if } i \neq j \text { and } j \equiv 1(\bmod 2)
\end{array}\right.
$$

if

$$
c_{s+i, s+j}=\left\{\begin{array}{l}
m_{i, j} c_{-1, j-i-1}+k_{i, j} c_{-1, j-i-2} \text { for } j \equiv 0(\bmod 2) \\
m_{i, j} c_{-1, j-i-1} \text { for } j \equiv 1(\bmod 2)
\end{array}\right.
$$

where $m_{i, j}$ and $k_{i, j}$ are in $Z_{2}$.

To establish the necessity of the condition of the theorem, we proceed by induction on $n$. The case $n=2$ is straightforward in view of the preceding lemmas and, for the induction step, we make the following definitions and state a lemma about them:

Definition. If $A$ is an automorphism of $\mathrm{B}\left(2^{n+1}\right)$ with matrix 
$\left(c_{i, j}\right),-1 \leqq i, j \leqq 2 t-2$, relative to the canonical basis of $B\left(2^{n+1}\right)$, then the restriction of $A$ to $B\left(2^{n}\right)$ is the linear transformation $A^{\prime}$ of $B\left(2^{n}\right)$ onto itself whose matrix $\left(d_{i, j}\right),-1 \leqq i, j \leqq t-2$, relative to the canonical basis of $B\left(2^{n}\right)$ is defined by:

$$
d_{i, j}=\left\{\begin{array}{l}
c_{i, j} \text { for }-1 \leqq i, j \leqq s-2 \\
c_{s+i, j} \text { for } s-1 \leqq i \leqq t-2 \text { and }-1 \leqq j \leqq s-2 \\
c_{i, s+j} \text { for }-1 \leqq i \leqq s-2 \text { and } s-1 \leqq j \leqq t-2 \\
c_{s+i, s+j} \text { for } s-1 \leqq i, j \leqq t-2
\end{array}\right.
$$

Definition. If $A$ is an automorphism of $B\left(2^{n}\right)$ with matrix $\left(c_{i, j}\right),-1 \leqq i, j \leqq t-2$, relative to the canonical basis of $B\left(2^{n}\right)$, then the linear transformation of $B\left(2^{n+1}\right)$ induced by $A$ is the linear transformation $A^{*}$ of $B\left(2^{n+1}\right)$ onto itself whose matrix $\left(b_{i, j}\right),-1 \leqq i$, $j \leqq 2 t-2$, relative to the canonical basis of $B\left(2^{n+1}\right)$ is defined by:

For

$$
\begin{aligned}
& -1 \leqq i, j \leqq s-2, \\
& b_{i, j}=b_{s+i, s+j}=c_{i, j}, \\
& b_{t+i, t+j}=b_{3 s+i, 3 s+j}=c_{s+i, s+j}, \\
& b_{t+i, j}=b_{3 s+i, s+j}=c_{s+i, j}, \\
& b_{i, t+j}=b_{s+i, 3 s+j}=c_{i, s+j}, \text { and } \\
& b_{s+i, j}=b_{i, s+j}=b_{3 s+i, t+j}=b_{t+i, 3 s+j}=b_{3 s+i, j}=b_{t+i, s+j} \\
& \quad=b_{s+i, t+j}=b_{i, 3 s+j}=0 .
\end{aligned}
$$

Lemma 7. (i) If $A$ is an automorphism of $B\left(2^{n+1}\right)$, then the restriction $A^{\prime}$ of $A$ to $B\left(2^{n}\right)$ is an automorphism of $B\left(2^{n}\right)$.

(ii) If $A$ is an automorphism of $B\left(2^{n}\right)$, then the linear transformation $A^{*}$ of $B\left(2^{n+1}\right)$ induced by $A$ is an automorphism of $B\left(2^{n+1}\right)$.

The induction step then proceeds as follows: We assume that every automorphism of $B\left(2^{n}\right)$ has matrix of the form $A_{n}$ relative to the canonical basis of $B\left(2^{n}\right)$ and we let $A$ be an automorphism of $B\left(2^{n+1}\right)$ with matrix $\left(d_{i, j}\right),-1 \leqq i, j \leqq 2 t-2$, relative to the canonical basis of $B\left(2^{n+1}\right)$. We must show that $\left(d_{i, j}\right)$ satisfies (i)-(ix).

By the induction hypothesis and Lemmas 5 and 7, we have (i)-(iv). Lemma 1 establishes (v) and (vi)-(ix) follow from the induction hypothesis and Lemmas 4 and 6 . Thus we have that $\left(d_{i, j}\right),-1 \leqq i$, $j \leqq 2 t-2$, is of the form $A_{n+1}$, completing the induction. Therefore every automorphism of $B\left(2^{n}\right), n \geqq 2$, has matrix of the form $A_{n}$ relative to the canonical basis of $B\left(2^{n}\right)$.

To establish the sufficiency of the condition we first show that $\operatorname{det} A_{n}=1$ for $n \geqq 2$. This is accomplished by expanding $\operatorname{det} A_{n}$ by the cofactors of its first column, expanding the resulting $(t-1) \times(t-1)$ 
determinant by the cofactors of its first row, expanding the resulting $(t-2) \times(t-2)$ determinant by the cofactors of its first column, and continuing to alternate in this manner. In view of Lemmas 1,3 and 4 , after $t-2$ such steps we have

$$
\operatorname{det} A_{n}=\left|\begin{array}{ll}
1 & c_{-1,0} \\
0 & 1
\end{array}\right|=1
$$

This fact about the determinant says that $A_{n}$ is the matrix relative to the canonical basis of $B\left(2^{n}\right)$ of a nonsingular linear transformation $A$ of $B\left(2^{n}\right)$ onto itself. Hence it only remains to show that $A$ preserves products of the basis elements of $B\left(2^{n}\right)$ and this may be checked by a straightforward but lengthy calculation. This completes the proof.

3. The automorphism groups. At this point we know that the automorphism group $\mathscr{A}_{n}$ of $B\left(2^{n}\right)$ over $Z_{2}$ is the group formed by all matrices of the form $A_{n}$ under matrix multiplication. From the definition of the matrices $A_{n}, n \geqq 2$, it follows that such a matrix has $3 q$ elements $a_{i}$ and $r-1$ elements $b_{j}$ in its first row. Since any matrix of the form $A_{n}$ is completely determined by the elements of its first row, this says that the order of $\mathscr{A}_{n}$ is $2^{3 q+r-1}=2^{5 q-1}$.

In order to examine the structure of $\mathscr{A}_{n}$, we make the following

DeFinition. For $n \geqq 2$, let

$$
\begin{aligned}
& I_{1}^{n}=\{i: 0 \leqq i \leqq s-2, i \not 3(\bmod 4)\}, \\
& I_{2}^{n}=\{s+2 i-2: 2 \leqq i \leqq r\} \text { and } \\
& I^{n}=I_{1}^{n} \cup I_{2}^{n} .
\end{aligned}
$$

Then $I^{n}$ is a subset of $\{i: 0 \leqq i \leqq t-2\}$ and consists of $5 q-1$ elements.

For $i$ in $I^{n}$, define $G_{i}$ as follows:

(i) If $i$ is in $I_{1}^{n}, G_{i}$ is the matrix of the form $A_{n}$ with $a_{i}=1$, $a_{j}=0$ for $j$ in $I_{1}^{n}$ and $j \neq i$, and $b_{2 k}=0$ for $2 \leqq k \leqq r$.

(ii) If $i$ is in $I_{2}^{n}, G_{i}$ is the matrix of the form $A_{n}$ with $b_{i-s+2}=$ $1, b_{j-s+2}=0$ for $j$ in $I_{2}^{n}$ and $j \neq i$, and $a_{k}=0$ for $k$ in $I_{1}^{n}$.

Denote by $\left(i_{1}, i_{2}, \cdots, i_{m}\right)$, where $i_{j}$ is in $I^{n}$ for $1 \leqq j \leqq m$ and $i_{1}<i_{2}<\cdots<i_{m}$, the matrix of the form $A_{n}$ in which for each $j=$ $1,2, \cdots, m, a_{i_{j}}=1$ if $i_{j}$ is in $I_{1}^{n}$ and $b_{i_{j-s+2}}=1$ if $i_{j}$ is in $I_{2}^{n}$ while $a_{k}=0$ for $k$ in $I_{1}^{n}$ and $k \neq i_{j}$ for any $j=1,2, \cdots, m$ and $b_{k-s+2}=0$ for $k$ in $I_{2}^{n}$ and $k \neq i_{j}$ for any $j=1,2, \cdots, m$. Clearly any element of $\mathscr{A}_{n}$ can be expressed in the form $\left(i_{1}, i_{2}, \cdots, i_{m}\right)$ for some $i_{1}, i_{2}, \cdots, i_{m}$.

Using a technique due to Bobo [1], we can show that the set $\left\{G_{i}: i\right.$ in $\left.I^{n}\right\}$ generates $\mathscr{A}_{n}$. Finally, we determine the commutator subgroup of $\mathscr{A}_{n}$ by using a straightforward induction on $n$ together 
with the properties of matrix multiplication and matrices of the form $G_{i}$. The results are summarized in the following

THEOREM. The automorphism group $\mathscr{A}_{n}$ of the Jordan algebra $B\left(2^{n}\right), \quad n \geqq 2$, can be described abstractly as the group generated by the $5\left(2^{n-2}\right)-1$ generators $G_{i}$ where $i$ is in $I^{n}$ and where $G_{i}^{2}=I$ for all $i$ in $I^{n}$, $I$ being the $t \times t$ identity matrix. Moreover, the commuting relations among the generators of $\mathscr{A}_{n}$ may be described inductively as follows:

In $\mathscr{A}_{2}, G_{0} G_{1} \neq G_{1} G_{0}$ but $G_{0} G_{1}=G_{2} G_{6} G_{1} G_{0}$. For all other $i$ and $j$ in $I^{2}, G_{i} G_{j}=G_{j} G_{i}$.

If the commuting relations among the generators $G_{i}^{\prime}$, $i$ in $I^{n-1}$, of $\mathscr{A}_{n-1}$ are known, the commuting relations in $\mathscr{A}_{n}$ are given by:

If $i$ and $m$ are in $I_{1}^{n-1}$ with $i, m \neq 0$ and $i \neq m$ and if $j$ and $k$ are in $I_{2}^{n-1}$ with $j \neq k$, then

(a) If $i \equiv 1(\bmod 4)$,

$G_{0} G_{i}=G_{i+1} G_{s+i+1} G_{i} G_{0}$,

$G_{0} G_{i+r}=G_{r+i+1} G_{s+r+i+1} G_{i+r} G_{0}$,

$G_{i} G_{r}=G_{r+i+1} G_{r} G_{i}$, and

$G_{i} G_{s+r}=G_{s+r+i+1} G_{s+r} G_{i}$.

(b) If $G_{i}^{\prime} G_{m}^{\prime}=G_{i+m+1}^{\prime} G_{m}^{\prime} G_{i}^{\prime}$,

$G_{i} G_{m}=G_{i+m+1} G_{m} G_{i}$, and

$G_{i} G_{m+r}=G_{r+i+m+1} G_{m+r} G_{i}$.

(c) If $G_{i}^{\prime} G_{j}^{\prime}=G_{i+j+1}^{\prime} G_{j}^{\prime} G_{i}^{\prime}$,

$G_{i} G_{j+r}=G_{r+i+j+1} G_{j+r} G_{i}$;

$G_{i} G_{j+s}=G_{s+i+j+1} G_{j+s} G_{i}$, and

$G_{i+r} G_{j+r}=G_{s+i+j+1} G_{j+r} G_{i+r}$.

Otherwise, $G_{e} G_{f}=G_{f} G_{e}$ for $e$ and $f$ in $I^{n}$.

The structure of the group $\mathscr{A}_{2}$ of order 16 becomes clearer if it is recognized as the direct product of two familiar groups. Since $I_{1}^{2}=\{0,1,2\}$ and $I_{2}^{2}=\{6\}, \mathscr{A}_{2}$ is generated by $G_{0}, G_{1}, G_{2}$, and $G_{6}$. Let $H_{1}$ be the subgroup of $\mathscr{A}_{2}$ generated by $G_{0}$ and $G_{1}$. Then, if $a=G_{1} G_{0}$ and $b=G_{0}$, direct computation using the commuting relations in $\mathscr{A}_{2}$ yields $H_{1}=\left\{I, a, b, a b, a^{2}, a^{3}, a^{2} b, a^{3} b\right\} \cong$ the dihedral group $D_{4}$. If $H_{2}=\left\{I, G_{2}\right\}$ then both $H_{1}$ and $H_{2}$ are normal in $\mathscr{A}_{2}, H_{1} \cap H_{2}=\{I\}$, and $H_{1} H_{2}=\mathscr{A}_{2}$. Hence

$$
\mathscr{A}_{2} \cong D_{4} \times Z_{2}
$$

where $D_{4}$ is the dihedral group of order eight and $Z_{2}$ is the cyclic group of order two.

Detailed proofs of some of the results summarized in this paper 
may be found in the author's doctoral thesis written at the University of Virginia under Eugene C. Paige.

\section{REFERENCES}

1. E. R. Bobo, Automorphism groups of Jordan algebras, Nagoya Math. J. 32 (1968), 227-235.

2. E. C. Paige, Jr., Jordan algebras of characteristic two, Dissertation, University of Chicago, Chicago, Illinois, 1954.

3. J. B. Stroud, Simple Jordan algebras of characteristic two, Dissertation, University of Virginia, Charlottesville, Virginia, 1965.

Received May 21, 1969. This research was supported in part by the Danforth Foundation.

BowdoIN COLLEge

Brunswick, MaINe 



\title{
PACIFIC JOURNAL OF MATHEMATICS
}

\author{
EDITORS
}

H. SAMELSON

Stanford University

Stanford, California 94305

J. DugunduI

Department of Mathematics

University of Southern California

Los Angeles, California 90007

RICHARD PIERCE

University of Washington

BASIL GORDON*

University of California

Seattle, Washington 98105

Los Angeles, California 90024

\section{ASSOCIATE EDITORS}

E. F. BeCKenbaCh

B. H. NeumanN

F. WOLF

K. YosHIDA

\section{SUPPORTING INSTITUTIONS}

\author{
UNIVERSITY OF BRITISH COLUMBIA \\ CALIFORNIA INSTITUTE OF TECHNOLOGY \\ UNIVERSITY OF CALIFORNIA \\ MONTANA STATE UNIVERSITY \\ UNIVERSITY OF NEVADA \\ NEW MEXICO STATE UNIVERSITY \\ OREGON STATE UNIVERSITY \\ UNIVERSITY OF OREGON \\ OSAKA UNIVERSITY \\ UNIVERSITY OF SOUTHERN CALIFORNIA
}

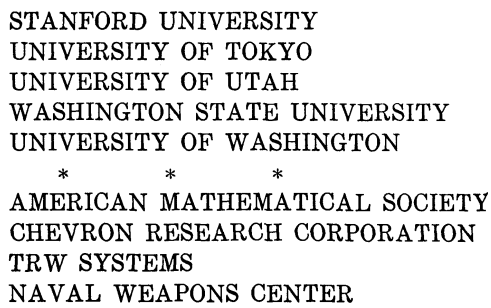

The Supporting Institutions listed above contribute to the cost of publication of this Journal, but they are not owners or publishers and have no responsibility for its content or policies.

Mathematical papers intended for publication in the Pacific Journal of Mathematics should be in typed form or offset-reproduced, double spaced with large margins. Underline Greek letters in red, German in green, and script in blue. The first paragraph or two must be capable of being used separately as a synopsis of the entire paper. It should not contain references to the bibliography. Manuscripts, in duplicate if possible, may be sent to any one of the four editors. Please classify according to the scheme of Math. Rev. 36, 1539-1546. All other communications to the editors should be addressed to the managing editor, Richard Arens, University of California, Los Angeles, California, 90024.

50 reprints are provided free for each article; additional copies may be obtained at cost in multiples of 50 .

The Pacific Journal of Mathematics is published monthly. Effective with Volume 16 the price per volume (3 numbers) is $\$ 8.00$; single issues, $\$ 3.00$. Special price for current issues to individual faculty members of supporting institutions and to individual members of the American Mathematical Society: $\$ 4.00$ per volume; single issues $\$ 1.50$. Back numbers are available.

Subscriptions, orders for back numbers, and changes of address should be sent to Pacific Journal of Mathematics, 103 Highland Boulevard, Berkeley, California, 94708.

PUBLISHED BY PACIFIC JOURNAL OF MATHEMATICS, A NON-PROFIT CORPORATION

Printed at Kokusai Bunken Insatsusha (International Academic Printing Co., Ltd.), 7-17, Fujimi 2-chome, Chiyoda-ku, Tokyo, Japan.

* Acting Managing Editor. 


\section{Pacific Journal of Mathematics}

\section{Vol. 32, No. 3 \\ March, 1970}

Shair Ahmad, Dynamical systems of characteristic $0^{+} \ldots \ldots \ldots \ldots \ldots$

Charles A. Akemann and Bernard Russo, Geometry of the unit sphere of a $C^{*}$-algebra and its dual............................ 575

Philip Bacon, The compactness of countably compact spaces ......... 587

Richard Blaine Barrar and Henry Loeb, On the continuity of the nonlinear Tschebyscheff operator ............................ 593

L. Carlitz, Factorization of a special polynomial over a finite field ....... 603

Joe Ebeling Cude, Compact integral domains .................... 615

Frank Rimi DeMeyer, On automorphisms of separable algebras. II . . . . . 621

James B. Derr, Generalized Sylow tower groups .................. 633

Raouf Doss, Some inclusions in multipliers ................... 643

Mary Rodriguez Embry, The numerical range of an operator........... 647

John Froese, Domain-perturbed problems for ordinary linear differential

operators..................................... 651

Zdeněk Frolík, Absolute Borel and Souslin sets ..................... 663

Ronald Owen Fulp, Tensor and torsion products of semigroups .......... 685

George Grätzer and J. Płonka, On the number of polynomials of an

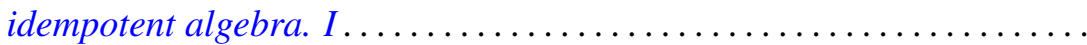

Newcomb Greenleaf and Walter Read, Positive holomorphic differentials on

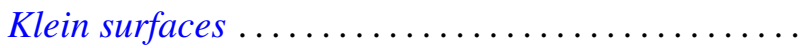

John Willard Heidel, Uniqueness, continuation, and nonoscillation for a second order nonlinear differential equation ................. 715

Leon A. Henkin, Extending Boolean operations................... 723

R. Hirshon, On hopfian groups .......................... 753

Melvin Hochster, Totally integrally closed rings and extremal spaces ..... 767

R. Mohanty and B. K. Ray, On the convergence of a trigonometric integral ..................................

Michael Rich, On a class of nodal algebras .................... 787

Emile B. Roth, Conjugate space representations of Banach spaces ........ 793

Rolf Schneider, On the projections of a convex polytope .............. 799

Bertram Manuel Schreiber, On the coset ring and strong Ditkin sets ...... 805

Edgar Lee Stout, Some remarks on varieties in polydiscs and bounded

holomorphic functions .........................

James Edward Ward, Two-groups and Jordan algebras . 